\section{Kidney Blood Pressure Research}

\title{
Angiotensin II Type I Receptor Agonistic Autoantibody Induces Podocyte Injury via Activation of the TRPC6- Calcium / Calcineurin Pathway in Pre-Eclampsia
}

\author{
Ying Yu Lihong Zhang ${ }^{a}$ Guang Xu ${ }^{d}$ Zhenghong Wu ${ }^{b}$ Qian Lib Yong Gu ${ }^{a, c}$ \\ Jianying Niu ${ }^{\mathrm{a}}$ \\ aDivision of Nephrology, The Fifth People's Hospital of Shanghai, Fudan University, Shanghai, \\ bDepartment of Gynaecology and Obstetrics, The Fifth People's Hospital of Shanghai, Fudan University, \\ Shanghai, 'Division of Nephrology, Huashan Hospital, Fudan University, Shanghai, dDivision of \\ Nephrology, The Central Hospital of Nanyang, Nanyang, Henan Province, China
}

\section{Key Words}

Pre-eclampsia Podocyte Angiotensin II type I receptor agonistic autoantibody /AT1-AA • TRPC6 • Calcium/calcineurin

\begin{abstract}
Background/Aims: Angiotensin II type I receptor agonistic autoantibody (AT1-AA) is closely related to pre-eclampsia, which is characterized by proteinuria and hypertension. AT1-AA has been shown to enhance the effect of Angll in pre-eclampsia, such as production of endothelin-1, activation of ROS, and vasoconstriction, which are considered to be associated with hypertension; however, whether or not AT1-AA participates in podocyte damage leading to the generation of proteinuria has not been reported. In this study we investigated the role of pre-eclamptic serum AT1-AA on podocytes and the mechanism underlying the generation of proteinuria. Methods: The levels of AT1-AA isolated from pre-eclamptic sera were determined by an enzyme-linked immunosorbent assay. Human podocytes were cultured in vitro and treated with various concentrations of AT1-AA. Whether or not an ERK1/2 inhibitor and TRPC6 siRNA inhibit the effect of AT1-AA on podocytes was determined. Western blot was used to detect the expression of podocyte-specific proteins (nephrin, synaptopodin, and podocin) and the phosphorylation of ERK1/2 and TRPC6. The arrangement of F-actin was observed by immunofluorescence. A Calcineurin Cellular Activity Assay Kit was used to detect calcineurin activity. Changes in the intracellular $\mathrm{Ca}^{2+}$ concentration was determined by confocal laser. Results: AT1-AA induced a decrease in podocyte-specific protein expression and calcineurin activity and increased expression of p-ERK $1 / 2$ and TRPC6 protein and the intracellular
\end{abstract}




\section{Kidney Blood Pressure Research}

Kidney Blood Press Res 2018;43:1666-1676

\begin{tabular}{l|l}
\hline DOI: 10.1159/000494744 & (C) 2018 The Author(s). Published by S. Karger AG, Base
\end{tabular}

Published online: 31 October 2018

www.karger.com/kbr

$\mathrm{Ca}^{2+}$ concentration. Immunofluorescence revealed rearrangement of F-actin. PD98059, an inhibitor of ERK1/2, and TRPC6 siRNA attenuated the decreased expression of podocytespecific proteins and decreased intracellular $\mathrm{Ca}^{2+}$ concentration. The expression of TRPC 6 was reduced following the addition of ERK1/2 inhibitor. Conclusion: AT1-AA induced podocyte damage in a dose-dependent manner. The underlying mechanism might involve activation of the TRPC6 -calcium/calcineurin pathway. This study provides new details regarding podocyte injury and the mechanism underlying the generation of proteinuria in pre-eclampsia.

(C) 2018 The Author(s)

Published by S. Karger AG, Basel

\section{Introduction}

Pre-eclampsia (PE) is a leading cause of maternal and fetal morbidity and mortality during the perinatal period. PE is a systemic syndrome that is described as the new onset of hypertension after week 20 of pregnancy combined with proteinuria, other maternal organ dysfunction, such as renal insufficiency, liver involvement, neurological or haematological complications, uteroplacental dysfunction, or fetal growth restriction [1-3]. Although PE has been the focus of research interest of countless studies, the mechanism underlying the pathogenesis of kidney injury in PE is unknown. Recently, injury to the podocyte, an important component of the glomerular filtrating barrier, has been considered to contribute to the development of proteinuria in PE [4-6].

Angiotensin II type I receptor agonistic autoantibody (AT1-AA), as the name implies, functions by binding with the 7 amino acid sequence (I-H-R-N-V-F-F-I-I-N-T-N-I-T-V-C-AF-H-Y-E-SQ-N-S-T-L) on the second extracellular loop of AT1 receptor. In 1999, Wallukat et al. [7] first detected AT1-AA in gravidas with PE. The effects of AT1-AA are now known to include activation of oxidative stress, calcineurin and nuclear factor kappa- $\beta$, an increase in the production of endothelin-1 and sFlt- 1 , and induction of $\mathrm{Ca}^{2+}$ release in vascular smooth muscle cells [8-10]. AT1-AA has important properties involving Ang II-mediated effects on the AT1 receptor. It has been reported that Ang II induces calcium/calcineurin signaling and podocyte injury [11]; however, it is unclear whether or not ATI-AA can activate calcium/ calcineurin signaling and the role in podocyte injury has not been reported.

The canonical transient receptor potential (TRPC) family is an important non-selective $\mathrm{Ca}^{2+}$ permeable cation channel and is expressed in the plasma membrane of many tissues $[12,13]$. TRPC6 has been increasingly studied because TRPC6 is associated with family familial focal segmental glomerulosclerosis [14-17]. TRPC6 is a basic component of the slit diaphragm of podocytes. Abnormal expression of TRPC6 is involved in the pathology of podocyte damage by increasing the $\mathrm{Ca}^{2+}$ current [18-20]. Several lines of evidence have demonstrated that phosphorylation of ERK increases the expression of TRPC6 and causes cell damage [21, 22]. Nijenhuis et al. [23] reported that AngII induces the up-regulation of TRPC6 through the Ca2+/calcineurin pathway [23].

In the present study we hypothesized that AT1-AA is responsible for podocyte injury and the TRPC6-calcium/ calcineurin pathway is involved in downstream signaling activated by AT1-AA in the podocyte.

\section{Materials and Methods}

\section{Sera collection}

Ten patients with PE were enrolled from the Department of Gynecology and Obstetrics of The Fifth People's Hospital of Shanghai (Fudan University, Shanghai, China). The study protocol was approved by the Ethics Committee of the Fifth People's Hospital of Shanghai and informed written consent was obtained from all patients. PE was diagnosed by the new onset of high blood pressure (systolic pressure $\geq 140$ $\mathrm{mmHg}$ and /or diastolic pressure $\geq 90 \mathrm{mmHg}$ ) and proteinuria $(300 \mathrm{mg} / 24 \mathrm{~h}$ or $>1+$ protein in a random urine specimen) after 20 weeks gestation. The exclusion criteria were as follows: chronic hypertension; 


\section{Kidney Blood Pressure Research}

Kidney Blood Press Res 2018;43:1666-1676

\begin{tabular}{l|l}
\hline DOI: 10.1159/000494744 & (c) 2018 The Author(s). Published by S. Karger AG, Base
\end{tabular}

Published online: 31 October 2018

www.karger.com/kbr renal disease; diabetes mellitus and endocrine or autoimmune diseases. Fasting blood samples were collected from all of the study participants via the cubital veins and centrifuged at $3000 \mathrm{rpm}$ for 10 $\min$ at $4^{\circ} \mathrm{C}$ to separate the serum. The sera were isolated by affinity chromatography and stored at $-80^{\circ} \mathrm{C}$. The clinical features of the participants are summarized in Table 1.

\section{Autoantibody purification}

Peptide synthesis: The peptide corresponding
Table 1. Clinical features of participants

\begin{tabular}{lc}
\hline Characteristics & Value \\
\hline Age(years) & $31.9 \pm 4.67$ \\
Body mass index(BMI) & $32.3 \pm 4.21$ \\
Gestation weeks until delivery (weeks) & $36.93 \pm 2.32$ \\
Systolic pressure (mmHg) & $159.5 \pm 15.24$ \\
Diastolic pressure (mmHg) & $97.9 \pm 13.19$ \\
24-h urinary protein (g/24h) & $2.9 \pm 3.93$ \\
Serum creatinine (umol/L) & $46.4 \pm 5.5$ \\
Serum uric acid (umol/L) & $355 \pm 45.97$ \\
Serum urea (mmol/L) & $3.3 \pm 0.96$ \\
eGFR(MDRD) & $126.2 \pm 9.13$ \\
\hline
\end{tabular}

to the sequence of the human AT1RECII

(165-191[I-H-R-N-V-F-F-I-I-N-T-N-I-T-V-C-A-F-H-Y-E-SQ-N-S-T-L]) was synthesized as antigen by GL Biochem Ltd (Shanghai, China).

Purification of AT1-AA: The total immunoglobulin G (IgG) was isolated from serum samples by HiTrap Protein G HP (GE/Amersham, USA) according to the manufacturer's instruction. The IgG was then passed through an affinity chromatography column containing CNBr-activated sepharose 4B gel (GE Healthcare Life Sciences, USA) conjugated with the peptide prepared previously. The IgG fraction which did not bind with the affinity chromatography column was designated as non-specific IgG (nIgG) and used as the control group. The IgG fraction bound to the column was AT1-AA. AT1-AA and nIgG were used immediately or stored at $-80^{\circ} \mathrm{C}$.

\section{Enzyme-linked immunoabsorbent assay (ELISA)}

The level of AT1-AA was detected by ELISA kit before purification. The serum samples were added to the plates for determination of AT1-AA concentration by ELISA. The operation is briefly described as follows. The samples were added to 96 -well ELISA plates incubated at $37^{\circ} \mathrm{C}$ for $30 \mathrm{~min}$, and then washed. The conjugate reagent was next added to the microplates. After incubating and washing, the microplates were incubated with color agent in the dark at $37^{\circ} \mathrm{C}$ for $10 \mathrm{~min}$. The reaction was terminated by stop buffer. The optical density (OD) was measured at $450 \mathrm{~nm}$ in a microplate reader. The concentration was calculated according to a standard curve. Then, the sera were used to isolate AT1-AA. Purified AT1-AA was measured in a similar fashion.

\section{Cell culture}

The immortalized human podocyte cell line was generously provided by Professor Zhihong Liu (Research Institute of Nephrology of the Jinling Hospital of Nanjing University School of Medicine, Nanjing, China). The cells were cultured as described previously. Briefly, the podocytes were grown at $33^{\circ} \mathrm{C}$ in a RPMI-1640 medium containing 10\% fetal bovine serum (FBS; Gibco, USA) and a mixture containing insulin, transferrin and selenium solution (ITS; Invitrogen, USA). After the cells grew to approximately $80 \%$ confluence, the cells were moved to a $37^{\circ} \mathrm{C}$ humidified atmosphere in the same medium for 10 - 14 days to induce differentiation. The medium was changed every 2 days. Then, the podocytes were treated with or without AT1-AA for $24 \mathrm{~h}$. We pre-treated the cells with PD98059 (10 uM) for $30 \mathrm{~min}$ and TRPC6 siRNA (25 $\mathrm{nM}$ ) for $48 \mathrm{~h}$ prior to AT1-AA exposure.

\section{Transfection of TRPC6 siRNA}

The cells were transiently transfected with TRPC6 siRNA or scrambled siRNA using the Lipofectamine ${ }^{\circledR}$ RNAiMAX Reagent (Invitrogen, USA) according to the manufacturer's instructions. Briefly, to silence TRPC6, we used TRPC6 siRNA (TRPC6-human-1011, TRPC6-human-1491, and TRPC6-human-985), as well as a negative siRNA to select the effective siRNA. The siRNAs were diluted with RNA-free water to prepare a $25 \mu \mathrm{M}$ solution. When the cells grew approximately 10 days in a $37^{\circ} \mathrm{C}$ incubator, we changed the complete medium to serum- and antibiotic-free medium. Then, we diluted $9 \mu \mathrm{l}$ of Lipofectamine® RNAiMAX Reagent in $150 \mu \mathrm{l}$ of 0 pti-MEM®Medium and $1 \mu \mathrm{l}$ of siRNA in $150 \mu \mathrm{l}$ of Opti-MEM®Medium per well. After that, we added the diluted siRNA to diluted Lipofectamine ${ }^{\circledR}$ RNAiMAX Reagent and incubated at room temperature for 5 min before addition to the wells. After $4-6 \mathrm{~h}$, we changed the medium with fresh complete medium. 


\section{Kidney Blood Pressure Research}

\begin{tabular}{|c|c|}
\hline $\begin{array}{l}\text { DOI: } 10.1159 / 000494744 \\
\text { Published online: } 31 \text { October } 2018\end{array}$ & $\begin{array}{l}\text { (c) } 2018 \text { The Author(s). Published by S. Karger AG, Basel } \\
\text { www.karger.com/kbr }\end{array}$ \\
\hline
\end{tabular}

Cells were harvested within 48 - $72 \mathrm{~h}$ after transfection for Western blot. The sequences of TRPC6 siRNAs were as follows:

Negative siRNA sense 5'-UUCUCCGAACGUGUCACGUTT-3', Anti-sense5'-ACGUGACACGUUCGGAGAATT-3'; TRPC6-Homo-1491 sense 5'-GGUGAUCACGGUCGCCCAATT-3', Anti-sense 5'-UUGGGCGACCGUGAUCACCTT-3'; TRPC6-Homo-1101 sense 5'-GCUGCCCACUGCCAGGAAUTT-3', Anti-sense 5'-AUUCCUGGCAGUGGGCAGCTT-3'; TRPC6-Homo-915 sense 5'-GCUUUGCUUCUAGCUAUUATT-3', Anti-sense 5'-UAAUAGCUAGAAGCAAAGCTT-3'.

\section{Western blot analysis}

Western blot analysis was performed following a standard protocol. The treated human podocytes were washed with cold PBS and harvested in a lysis buffer containing a protease and phosphorylase inhibitor cocktail on ice for $30 \mathrm{~min}$. Total protein was obtained by centrifuging at 12, $000 \mathrm{~g}$ for $15 \mathrm{~min}$ at $4^{\circ} \mathrm{C}$. The same amount of protein was loaded on $10 \%$ SDS-PAGE, then transferred onto PVDF membranes. The membranes were blocked with 5\% non-fat milk at room temperature for $1 \mathrm{~h}$ and incubated overnight at $4^{\circ} \mathrm{C}$ with primary antibodies against $\beta$-actin (mouse-to-human [1:1000], CST\#3700); p-ERK1/2 (rabbitto-human [1:2000], CST\#9101); total-ERK1/2 (mouse-to-human [1:1000], CST\#4695); TRPC6 (rabbit-tohuman [1:1000], CST\#7225); nephrin (rabbit-to-human [1:1000], ab58968); podocin (rabbit-to-human [1:2000], ab50339); synaptopodin (rabbit-to-human [1:1000], ab117702). The membranes were washed three times with TBS-T and correspondingly incubated with a peroxidase-conjugated secondary antibody (Cell Signaling Technology) for $1 \mathrm{~h}$ at room temperature. After thrice washing with $0.1 \%$ TBST, the signals were detected with enhanced chemiluminescence (ECL, Merck Millipore, USA). $\beta$-actin served as an internal control.

\section{Immunofluorescence}

Immunofluorescence staining was performed on the cells using a standard protocol. Briefly, after twice washing with ice-cold PBS, the cells were fixed with $4 \%$ paraformaldehyde at room temperature for $30 \mathrm{~min}$, permeabilized using $0.1 \%$ Triton X-100 for $15 \mathrm{~min}$, then blocked with 5\% BSA in PBS for 60 min at $37^{\circ} \mathrm{C}$. After thrice washing with PBS, the cells were incubated with the appropriate primary antibody dilutions (anti-F-actin [1:400], mouse-human, ab205) at $4^{\circ} \mathrm{C}$ overnight. After thrice washing, the cells were incubated with Alexa Fluor 594-conjugated goat anti-mouse secondary antibody (1:200, Jackson, USA) at room temperature for $60 \mathrm{~min}$. The nuclei were counterstained with DAPI (C1005-10 ml [1:50]; Beyotime, China;) for $5 \mathrm{~min}$ at room temperature. After washing, the samples were examined using fluorescence microscopy (Olympus, Tokyo, Japan).

\section{Calcineurin phosphatase activity assay}

The calcineurin (CaN) activity of human podocytes was measured using a Biomol Calcineurin Cellular Activity Assay Kit (Enzo Life Science, Germany) according to the manufacturer's instructions. In brief, the cells were lysed on ice in lysis buffer containing protease inhibitors. Then, the samples were passed through freshly prepared columns within desalting resin to remove free phosphate. Between samples, the columns were rinsed with phosphate-free water. An equal amount of sample was added to substrate with or without EGTA buffer and incubated at $30^{\circ} \mathrm{C}$ for $30 \mathrm{~min}$. Biomol Green reagent $(100 \mu \mathrm{l})$ was used to terminate reactions and read the OD value at $620 \mathrm{~nm}$. The CaN activity for each sample was calculated according to the following formula: $\mathrm{CaN}=$ total-EGTA buffer.

\section{Measurement of intracellular $\mathrm{Ca}^{2+}\left(\left[\mathrm{Ca}^{2+}\right] \mathrm{i}\right)$}

The treated cells were grown on a laser scanning confocal microscope and 1\% physiologic saline solution containing 0.02\% Pluronic F-127 (p2443; Sigma-Aldrich) and 5 MM Fluo-3/AM ( F1242; Invitrogen) was added for $45 \mathrm{~min}$ at $37^{\circ} \mathrm{C}$. After thrice washing with D-Hanks, the cells were incubated in HEPES buffer saline for $20 \mathrm{~min}$. The fluorescence intensity of Fluo-3 in the podocytes was recorded with a laser confocal scanning microscope (FV300; Olympus, Japan). The cells were then incubated with $5 \mu$ M ionomycin in a $5 \mathrm{mM}$ $\mathrm{Ca}^{2+}$ buffer and $5 \mu \mathrm{M}$ ionomycin in a $5 \mathrm{mM}$ EGTA buffer for measuring the maximal and minimal responses to $\mathrm{Ca}^{2+}$, respectively. The intracellular calcium concentration was calculated according to Grynkiewicz et al.. 


\section{Kidney Blood Pressure Research}

\section{Statistical analyses}

All data are expressed as the mean \pm SD of three independent experiments. Intergroup comparisons were made using one-way analysis of variance (ANOVA). Multiple comparison between the groups was performed using Tukey's test. The data were analyzed using GraphPad Prism 5.0 software. A p value $<0.05$ was considered statistically significance for all tests.

\section{Results}

AT1-AA level in PE

We determined the AT1AA levels in PE sera using ELISA. Before purification the AT1-AA concentration was $134.48 \pm 3.89 \mathrm{ng} / \mathrm{L}$ and after purification the AT1AA concentration was 190 . $95 \pm 12.07 \mathrm{ng} / \mathrm{L}$.

\section{Effect of AT1-AA purified from $P E$ patients on podocyte- specific proteins \\ To determine whether} or not AT1-AA exerts a harmful effect, we treated podocytes with various concentrations of AT1AA $(1: 10 \sim 1: 80)$ for $24 \mathrm{~h}$. The effect of AT1-AA on the expression of nephrin, podocin, and synaptopodin is shown in Fig 1. AT1-AA reduced the expression of nephrin, podocin, and synaptopodin in a dose-dependent manner.

\section{Kidney Blood Press Res 2018;43:1666-1676}

\begin{tabular}{l|l}
\hline DOI: 10.1159/000494744 & (c) 2018 The Author(s). Published by S. Karger AG, Basel
\end{tabular} Published online: 31 October 2018 www.karger.com/kbr

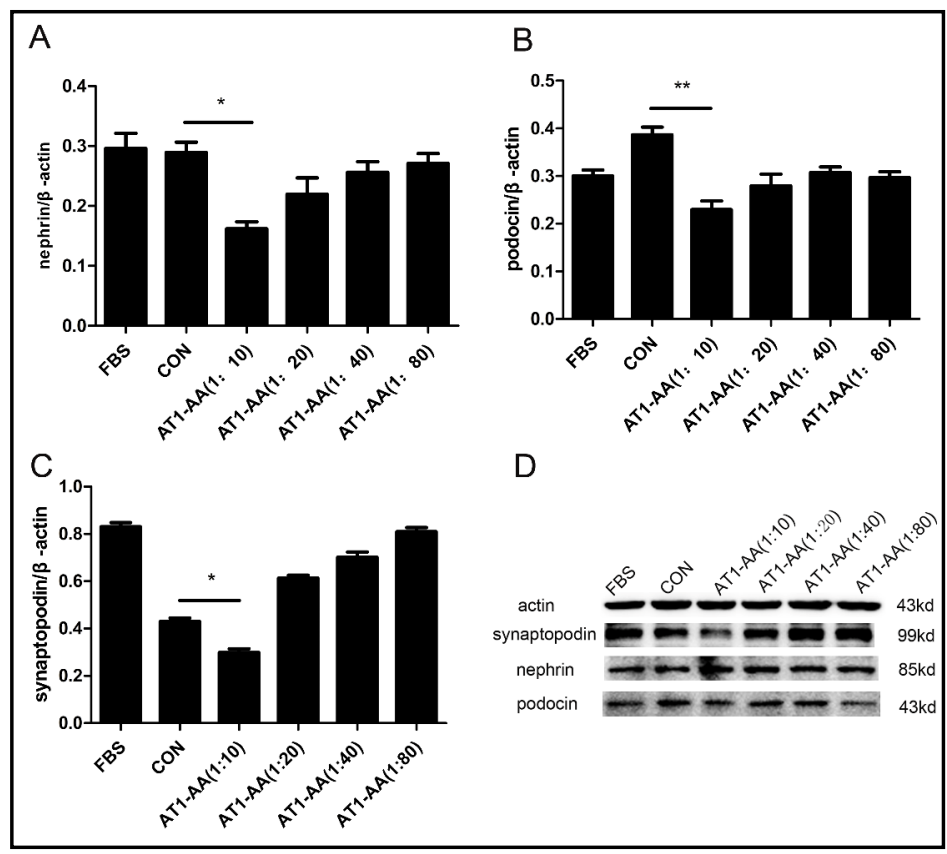

Fig. 1. Effects of various concentrations of AT1-AA on podocytespecific protein expression. The podocytes were incubated with fetal bovine serum (FBS), nIgG (Con), and AT1-AA at 1:10, 1:20, 1:40, and 1: 80 for $24 \mathrm{~h}$. (A-C) Analysis of nephrin, podocin, and synaptopodin expression in podocytes treated with various concentration of AT1-AA. (D) Podocyte-specific protein expression detected by Western blot. ${ }^{*} \mathrm{P}<0.05,{ }^{* *} \mathrm{P}<0.01$.

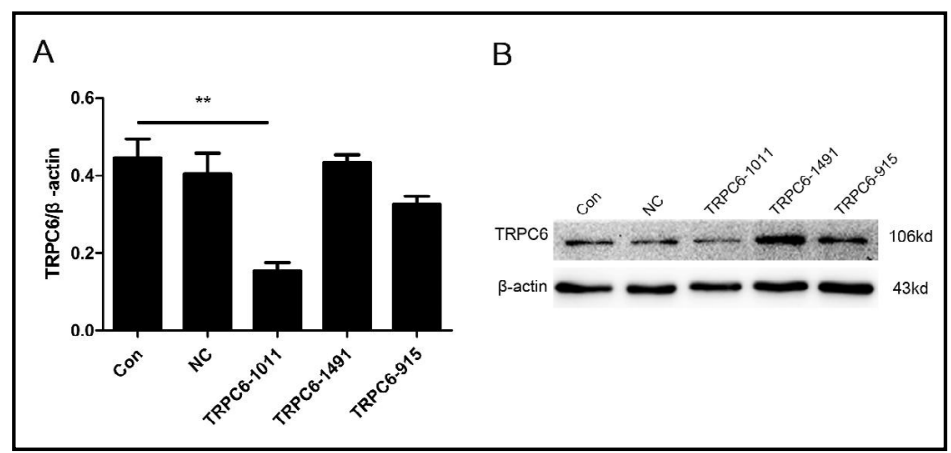

Fig. 2. The efficiency of transfection of TRPC6 siRNA on podocytes. The NC group represents the negative control siRNA group. (A) The relative expression of TRPC6 was assessed by densitometric analysis. (B) The expression of TRPC6 in podocytes was assessed by Western blotting after transfection for $48 \mathrm{~h} .{ }^{* *} \mathrm{P}<0.01$.

Therefore, we chose a titer of 1:10 in subsequent experiments.

\section{Effect of transfection of TRPC6 expression in podocytes}

To identify the function of TRPC6 on AT1-AA-stimulated podocytes, we used siRNA to knock down the expression of TRPC6. There were three pairs of siRNAs against TRPC6 and Western blot was applied to determine the effective pairs (Fig. 2A). The effect of TRPC6 siRNA 1101 decreased the expression of TRPC6 by $65 \%$ (Fig. 2B). Therefore, we chose TRPC6 


\section{Kidney Blood Pressure Research}

siRNA 1101 for subsequent experiments.

\section{Effect of transfection reagent on podocytes \\ To eliminate the} effect of transfection on podocytes, we established the following three groups: control group; vehicle group; and siRNA group. The special proteins of podocytes (nephrin, podocin, and synaptopodin) were assessed by Western blotting. As shown in Fig. 3, the transfection reagent had no effect on the expression of these proteins among the three groups.

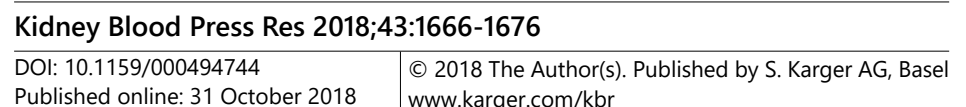

Published online: 31 October $2018 \quad$ www.karger.com/kbr

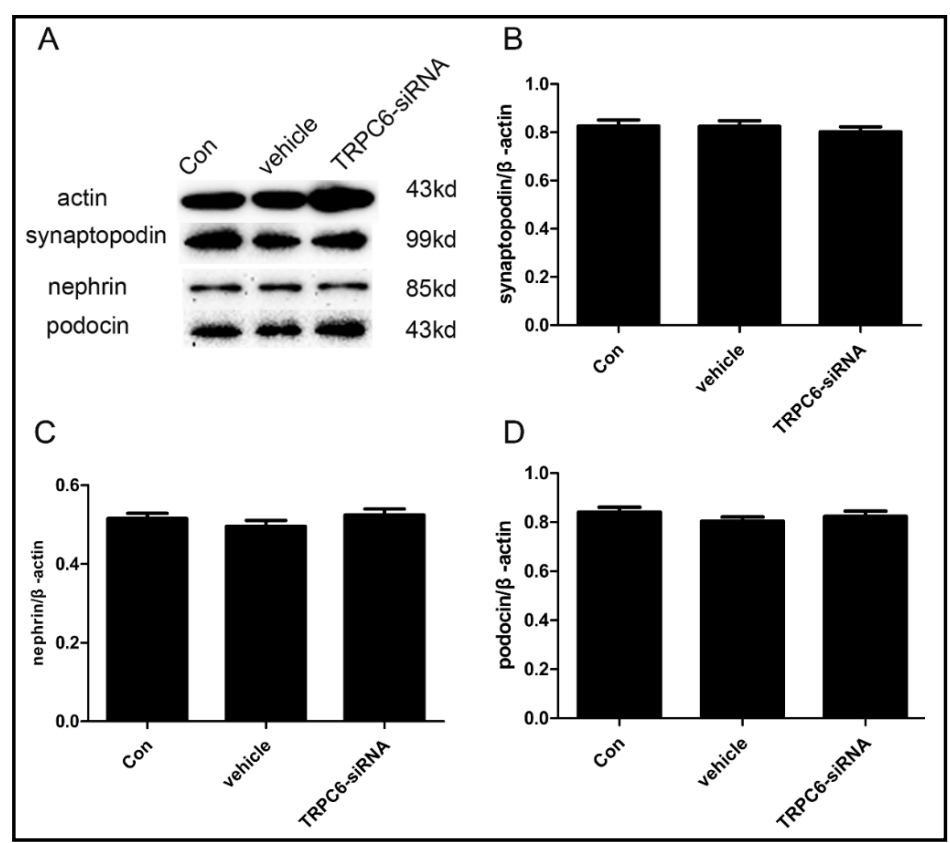

Fig. 3. Effects of transfection on podocyte-specific protein expression exposed to nIgG (Con), transfection reagent (vehicle), or SiRNA against TRPC6 (TRPC6 siRNA). (A) Podocyte-specific protein expression was detected by Western blot. (B-D) Expression of nephrin, podocin, and synaptopodin in podocytes.

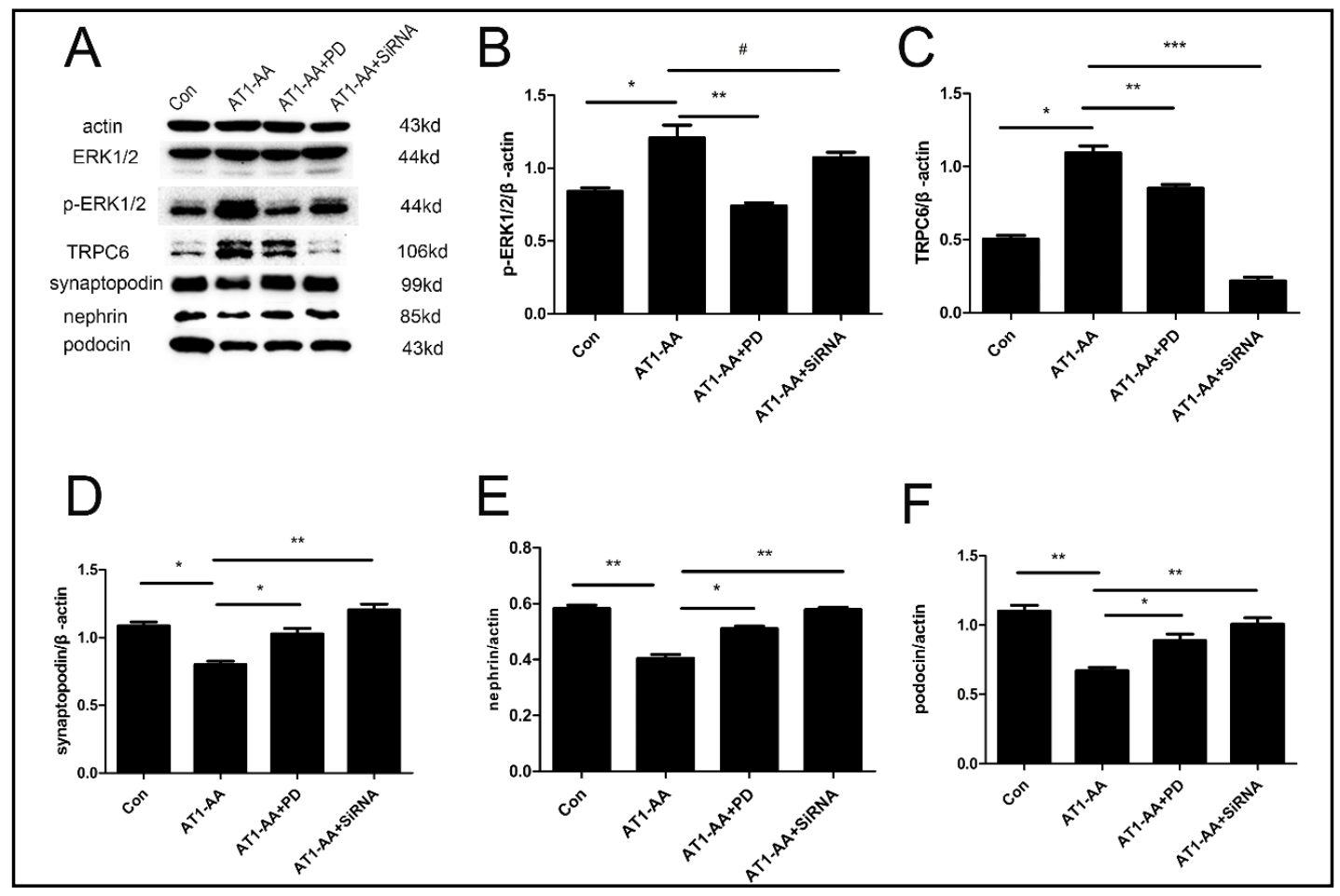

Fig. 4. Expression of TRPC6, p-ERK1/2, and podocyte-specific proteins in cells incubated with nIgG (Con), AT1-AA, AT1-AA plus PD98059 (AT1-AA+PD), and AT1-AA plus TRPC6 siRNA (AT1-AA+SiRNA). (A) The expression of TRPC6, p-ERK1/2, and podocyte-specific proteins was detected by Western blot. (B-D) The relative expression of proteins was analyzed by density measurement. ${ }^{*} \mathrm{P}<0.05,{ }^{* *} \mathrm{P}<0.01,{ }^{* * *} \mathrm{P}<0.001$, $\# \mathrm{P}>0.05$. 


\section{Kidney Blood Pressure Research}

Kidney Blood Press Res 2018;43:1666-1676

\begin{tabular}{l|l}
\hline DOI: $10.1159 / 000494744$ & (c) 2018 The Author(s). Published by S. Karger AG, Basel
\end{tabular} Published online: 31 October $2018 \quad$ www.karger.com/kbr

Calcineurin Pathway in PE

TRPC6 and $p$-ERK1/2 are involved in podocyte injury stimulated by AT1-AA

As shown in the Fig. 4, the expression of p-ERK1/2 and TRPC6 was significantly increased in the podocytes treated with AT1-AA compared with the cells incubated with nIgG. After the podocytes were pre-treated with ERK1/2 inhibitor or TRPC6 siRNA, the expression of the podocyte- specific proteins increased. The results revealed that ERK1/2 and TRPC6 have a role in podocyte injury induced by AT1-AA. Compared to the AT1-AA group, the expression of p-ERK1/2 changed little in the TRPC6 knockdown group. The expression of TRPC6 was significantly reduced in the PD group. The results demonstrated that ERK1/2 modulated the expression of TRPC6.

\section{Effect of AT1-AA on F-actin in podocytes}

F-actin is a cytoskeletal protein that is a crucial structure in foot processes of podocytes. The expression and arrangement of F-actin plays a vital role in podocyte function. As shown in Fig. 5, compared with other groups, the expression and arrangement of F-actin in the podocytes treated with AT1-AA was changed, including cortical F-actin ring formation and stress fiber attenuation. In addition, this change was attenuated by the addition of pd98059 or TRPC6 siRNA.

\section{Change in the concentration of intracellular $\mathrm{Ca}^{2+}$}

In agreement with previous studies, we showed that the concentration of intracellular $\mathrm{Ca}^{2+}$ increased in the AT1-AA group, which was blunted by PD98059 or TRPC6 siRNA (Fig 6A).

\section{Change in calcineurin phosphatase activity}

Fig. 6B shows that the AT1-AA group had decreased calcineurin phosphatase activity. The effect of AT-AA in down-regulation of calcineurin activity was partly relieved after PD administration or TRPC6 knockdown.

Discussion
PE, a leading direct
cause of maternal
morbidity and
mortality worldwide,
is a noteworthy risk
factor for end-stage
kidney disease (ESKD)
in later life [24]. As an
important structure of
glomerular filtration
membranes, podocytes
play an important role
in proteinuria. There
is growing evidence,
identified by us and
others, that podocyte
injury is involved
in the generation of
proteinuria in PE [25-
27]. AngII can induce
podocyte injury via
binding to AngII

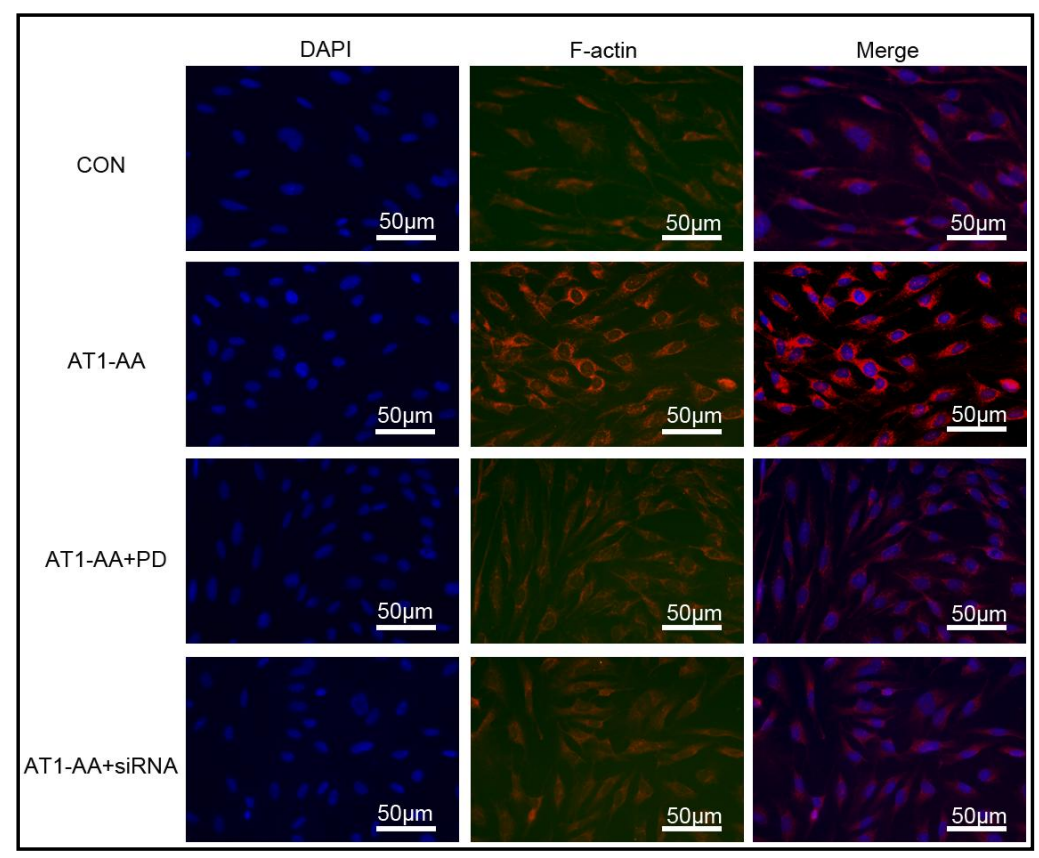

Fig. 5. Effects of AT1-AA on changes in F-actin in podocytes under control conditions (Con), AT1-AA (AT1-AA), and in the presence of TRPC6 siRNA (AT1-AA+siRNA) or PD98059 (AT1-AA+PD). F-actin was stained by red immunofluorescence and the nuclei were counterstained by DAPI. 


\section{Kidney Blood Pressure Research}

receptor [28]; however, our previous study showed that the expression of AngII and AT1 receptor in the kidney were decreased in a PE rat model. Wallukat et al. [7] discovered an autoantibody which can activate the AT1 receptor and imitate most functions of AngII [10, 29]. In the current study we established a PE podocyte injury model induced by AT1-AA and we showed that AT1-AA induced podocyte injury in a dose-dependent manner.

AngII has been reported to enhance TRPC6 expression and activate calcium/calcineurin signaling, which could induce podocyte injury $[30,31]$. To elucidate the mechanism underlying the effect of AT1-AA on podocyte injury, we verified the activation of TRPC6-calcium/calcineurin in podocytes treated with AT1-AA. Indeed, we found that AT1-AA up-regulates the expression of TRPC6 in cultured human podocytes and that the subsequent activation of calcium/calcineurin is responsible for podocyte injury. We conclude that the increased TRPC6 expression is a direct result of AT1-AA acting on the podocyte. Zhang et al. [32] previously suggested that AngII-induced TRPC6 expression might involve MAPK, ERK, JNK, and NF- $\kappa B$. To identify the possible novel mechanism underlying TRPC6-calcium/calcineurin signaling activation induced by AT1-AA, we detected the expression of ERK1/2. AT1-AA increased ERK1/2 protein expression, which is in agreement with our previous study [33]. When ERK1/2 inhibitor was administered in the podocytes treated with AT1-AA, we observed marked ameliorations in podocyte injury and a reduction of TRPC6; however, the expression of ERK1/2 was unrecognizable when we knocked down TRPC6. Regardless of the latter possibility, ERK1/2 regulates the expression of TRPC6.

We further demonstrated that AT1-AA induced calcium/calcineurin signaling activation in podocytes by increasing the expression of TRPC6. We inferred that the intracellular calcium concentration might have changed in the treated cells. This is because AngII is expected to lead to calcium influx in podocytes, and our current study clarified that the expression of TRPC6, a transient receptor potential ion channel the activation of which results in calcium entry into cells, was up-regulated by AT1-AA in podocytes. We also investigated the phosphatase activity of calcineurin. In the current study we found that the intracellular calcium concentration was increased, while the calcineurin phosphatase activity decreased. Since calcineurin is regulated by the calcium concentration, we assume that the decrease in calcium phosphatase activity was related to an increased intracellular calcium concentration [34].

In agreement with previous results, there was a cytoskeletal rearrangement in the treated podocytes, including cortical F-actin ring formation and stress fiber attenuation. This change was in agreement with the effect of AngII on podocytes [35]. TRPC6 knockdown or ERK1/2 inhibitor attenuated, not only this cytoskeleton change, but also the expression of podocyte-specific proteins.

In this study we demonstrated that AT1-AA is answerable for the activation of TRPC6calcium/calcineurin signaling and podocyte injury, including podocyte cytoskeletal rearrangement. In summary, our study was the first to demonstrate that AT1-AA induces

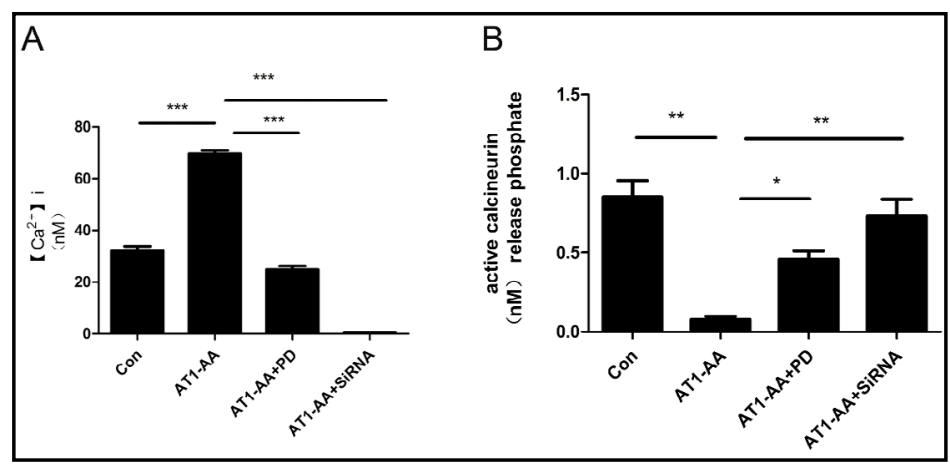

Fig. 6. Effect of AT1-AA on calcium/calcineurin in podocytes. (A)
Bar graph of intracellular calcium concentration in podocytes under control conditions (Con), after administration of AT1-AA (AT1-AA), administration of PD98059 (AT1-AA+PD). (B) Bar graph of calcineurin phosphatase activity. ${ }^{*} \mathrm{p}<0.05,{ }^{* *} \mathrm{P}<0.01,{ }^{* * *} \mathrm{P}<0.001$. 


\section{Kidney \\ Blood Pressure Research}

Kidney Blood Press Res 2018;43:1666-1676

\begin{tabular}{l|l}
\hline DOI: $10.1159 / 000494744$ & (c) 2018 The Author(s). Published by S. Karger AG, Basel
\end{tabular}

Published online: 31 October $2018 \quad$ www.karger.com/kbr

podocyte injury by up-regulating ERK1/2, which activates TRPC6-calcium/calcineurin signaling, forming a potentially deleterious feedback loop by enhancing expression of TRPC6 and ultimately leading to podocyte injury. In addition, our findings have increased our understanding of the mechanisms underlying AT1-AA-induced podocyte injury and provide a new therapeutic strategy in PE.

\section{Limitations}

This study was performed in vitro without an animal model. Whether or not this effect is the same in vivo requires further verification. We did not investigate the role of ARB, the blocker of the AT1 receptor, in AT1-AA-induced podocyte injury because of the small amount of antibodies that can be isolated from PE serum. We tried to acquire the autoantibodies using synthetic peptides in immune mice. Unfortunately, the injurious effect was not apparent.

\section{Acknowledgements}

This work was supported by grants from the Minhang District Leading Talent Project, the Minhang District Medical Speciality Project (2017MWTZ04), the Natural Science Foundation of Shanghai (16ZR1426900) and Natural Science Foundation of China (81570661).

\section{Disclosure Statement}

The authors declare they have no conflict of interest.

\section{References}

1 Sibai BM: Etiology and management of postpartum hypertension-preeclampsia. Am J Obstet Gynecol 2012;206:470-475.

-2 Nelson DB, Ziadie MS, McIntire DD, Rogers BB, Leveno KJ: Placental pathology suggesting that preeclampsia is more than one disease. Am J Obstet Gynecol 2014;210:61-66.

3 Mol BWJ, Roberts CT, Thangaratinam S, Magee LA, de Groot CJM, Hofmeyr GJ: Pre-eclampsia. Lancet 2016;387:999-1011.

4 Chen G, Zhang L, Jin X, Zhou Y, Niu J, Chen J, Gu Y: Effects of angiogenic factors, antagonists, and podocyte injury on development of proteinuria in preeclampsia. Reprod Sci 2013;20:579-588.

-5 Konieczny A, Ryba M, Wartacz J, Czyzewska-Buczynska A, Hruby Z, Witkiewicz W: Podocytes in urine, a novel biomarker of preeclampsia? Adv Clin Exp Med 2013;22:145-149.

-6 Garovic VD, Wagner SJ, Turner ST, Rosenthal DW, Watson WJ, Brost BC, Rose CH, Gavrilova L, Craigo P, Bailey KR, Achenbach J, Schiffer M, Grande JP: Urinary podocyte excretion as a marker for preeclampsia. Am J Obstet Gynecol 2007;196:320-321.

-7 Wallukat G, Homuth V, Fischer T, Lindschau C, Horstkamp B, Jupner A, Baur E, Nissen E, Vetter K, Neichel D, Dudenhausen JW, Haller H, Luft FC: Patients with preeclampsia develop agonistic autoantibodies against the angiotensin AT1 receptor. J Clin Invest 1999;103:945-952.

-8 LaMarca B, Parrish MR, Wallace K: Agonistic autoantibodies to the angiotensin II type i receptor cause pathophysiologic characteristics of preeclampsia. Gender Medicine 2012;9:139-146.

\$9 Brewer J, Liu R, Lu Y, Scott J, Wallace K, Wallukat G, Moseley J, Herse F, Dechend R, Martin JN, LaMarca B: Endothelin-1, oxidative stress, and endogenous angiotensin II: Mechanisms of angiotensin II type i receptor Autoantibody-Enhanced renal and blood pressure response during pregnancy. Hypertension 2013;62:886892.

10 Walther T, Stepan H: Agonist autoantibodies against the angiotensin AT1 receptor in renal and hypertensive disorders. Curr Hypertens Rep 2007;9:128-132. 


\section{Kidney \\ Blood Pressure Research}

11 Zhao Y, Wu J, Zhang M, Zhou M, Xu F, Zhu X, Zhou X, Lang Y, Yang F, Yun S, Shi S, Liu Z: Angiotensin II induces calcium/calcineurin signaling and podocyte injury by downregulating microRNA-30 family members. J Mol Med (Berl) 2017;95:887-898.

12 Yang Q Huang JH, Yao XQ Underwood MJ, Yu CM: Activation of canonical transient receptor potential channels preserves $\mathrm{Ca} 2+$ entry and endothelium-derived hyperpolarizing factor-mediated function in vitro in porcine coronary endothelial cells and coronary arteries under conditions of hyperkalemia. J Thorac Cardiovasc Surg 2014;148:1665-1673.

13 Abramowitz J, Birnbaumer L: Physiology and pathophysiology of canonical transient receptor potential channels. FASEB J 2009;23:297-328.

14 Winn MP, Conlon PJ, Lynn KL, Farrington MK, Creazzo T, Hawkins AF, Daskalakis N, Kwan SY, Ebersviller S, Burchette JL, Pericak-Vance MA, Howell DN, Vance JM, Rosenberg PB: A mutation in the TRPC6 cation channel causes familial focal segmental glomerulosclerosis. Science 2005;308:1801-1804.

15 Zhu B, Chen N, Wang ZH, Pan XX, Ren H, Zhang W, Wang WM: Identification and functional analysis of a novel TRPC6 mutation associated with late onset familial focal segmental glomerulosclerosis in Chinese patients. Mutat Res 2009;664:84-90.

16 Santin S, Ars E, Rossetti S, Salido E, Silva I, Garcia-Maset R, Gimenez I, Ruiz P, Mendizabal S, Luciano NJ, Pena A, Camacho JA, Fraga G, Cobo MA, Bernis C, Ortiz A, de Pablos AL, Sanchez-Moreno A, Pintos G, Mirapeix E, et al.: TRPC6 mutational analysis in a large cohort of patients with focal segmental glomerulosclerosis. Nephrol Dial Transplant 2009;24:3089-3096.

17 Yu H, Kistler A, Faridi MH, Meyer JO, Tryniszewska B, Mehta D, Yue L, Dryer S, Reiser J: Synaptopodin limits TRPC6 podocyte surface expression and attenuates proteinuria. J Am Soc Nephrol 2016;27:3308-3319.

18 Reiser J, Polu KR, Moller CC, Kenlan P, Altintas MM, Wei C, Faul C, Herbert S, Villegas I, Avila-Casado C, McGee M, Sugimoto H, Brown D, Kalluri R, Mundel P, Smith PL, Clapham DE, Pollak MR: TRPC6 is a glomerular slit diaphragm-associated channel required for normal renal function. Nat Genet 2005;37:739744.

19 Yu S, Yu L: Dexamethasone resisted podocyte injury via stabilizing TRPC6 expression and distribution. Evid Based Complement Alternat Med 2012;2012:652059.

20 Moller CC, Flesche J, Reiser J: Sensitizing the Slit Diaphragm with TRPC6 ion channels. J Am Soc Nephrol 2009;20:950-953.

21 Heiser JH, Schuwald AM, Sillani G, Ye L, Muller WE, Leuner K: TRPC6 channel-mediated neurite outgrowth in PC12 cells and hippocampal neurons involves activation of RAS/MEK/ERK, PI3K, and CAMKIV signaling. J Neurochem 2013;127:303-313.

-22 Chiluiza D, Krishna S, Schumacher VA, Schlondorff J: Gain-of-function mutations in transient receptor potential C6 (TRPC6) activate extracellular signal-regulated kinases 1/2 (ERK1/2). J Biol Chem 2013;288:18407-18420.

23 Nijenhuis T, Sloan AJ, Hoenderop JG, Flesche J, van Goor H, Kistler AD, Bakker M, Bindels RJ, de Boer RA, Moller CC, Hamming I, Navis G, Wetzels JF, Berden JH, Reiser J, Faul C, van der Vlag J: Angiotensin II contributes to podocyte injury by increasing TRPC6 expression via an NFAT-mediated positive feedback signaling pathway. Am J Pathol 2011;179:1719-1732.

-24 Vikse BE, Irgens LM, Leivestad T, Skjaerven R, Iversen BM: Preeclampsia and the risk of end-stage renal disease. N Engl J Med 2008;359:800-809.

25 Garovic VD: The role of the podocyte in preeclampsia. Clin J Am Soc Nephrol 2014;9:1337-1340.

-26 Weissgerber TL, Craici IM, Wagner SJ, Grande JP, Garovic VD: Advances in the pathophysiology of preeclampsia and related podocyte injury. Kidney Int 2014;86:445.

-27 Henao DE, Saleem MA: Proteinuria in preeclampsia from a podocyte injury perspective. Curr Hypertens Rep 2013;15:600-605.

28 Yu SY, Qi R, Zhao H: Losartan reverses glomerular podocytes injury induced by AngII via stabilizing the expression of GLUT1. Mol Biol Rep 2013;40:6295-6301.

29 Zhang W, Zheng Y, Liu F, Wang X, Jin Z, Zhi J: Mechanism of agonistic angiotensin II type I receptor autoantibody-amplified contractile response to Ang II in the isolated rat thoracic aorta. Acta Biochim Biophys Sin (Shanghai) 2015;47:851-856.

30 Shengyou Y, Li Y: The effects of siRNA-silenced TRPC6 on podocyte autophagy and apoptosis induced by AngII. J Renin Angiotensin Aldosterone Syst 2015;16:1266-1273. 


\section{Kidney

Yu et al.: AT1-AA Induces Podocyte Injury via Activation of the TRPC6-Calcium /

Calcineurin Pathway in PE

-31 Sonneveld R, van der Vlag J, Baltissen MP, Verkaart SA, Wetzels JF, Berden JH, Hoenderop JG, Nijenhuis T: Glucose specifically regulates TRPC6 expression in the podocyte in an AngII-dependent manner. Am J Pathol 2014;184:1715-1726.

32 Zhang H, Ding J, Fan Q, Liu S: TRPC6 up-regulation in Ang II-induced podocyte apoptosis might result from ERK activation and NF-kappaB translocation. Exp Biol Med (Maywood) 2009;234:1029-1036.

-33 Tian J, Zhang L, Zhou Y, Xiao J, Li S, Chen Y, Qiao Z, Niu J, Gu Y: Angiotensin-(1-7) attenuates damage to podocytes induced by preeclamptic serum through MAPK pathways. Int J Mol Med 2014;34:1057-1064.

-34 Kebabian JW: A phosphorylation cascade in the basal ganglia of the mammalian brain: Regulation by the D-1 dopamine receptor. A mathematical model of known biochemical reactions. J Neural Transm Suppl 1997;49:145-153.

-35 Hsu HH, Hoffmann S, Endlich N, Velic A, Schwab A, Weide T, Schlatter E, Pavenstadt H: Mechanisms of angiotensin II signaling on cytoskeleton of podocytes. J Mol Med (Berl) 2008;86:1379-1394. 